\title{
ESPAÑA EN LOS SIGLOS XI Y XII A TRAVÉS DE LA MIRADA DE TRES AUTORES HISPANO - HEBREOS ${ }^{1}$
}

Spain in the XI and XII centuries through the look of three Hebrews-Hispanic authors

Prof. Katia Lizana Salas Centro de Estudios Judaicos Universidad de Chile

Introducción:

Para comenzar con nuestra exposición, haremos un recorrido panorámico por la Península Ibérica, destacando los momentos históricos más importantes que dan cuenta del proceso de asentamiento del pueblo judío en España:

Existe una hipótesis que pretende que los hebreos habrían llegado junto con los fenicios a la Península, alrededor del siglo IX a.e.c.

La toponimia ha dado lugar a esta interpretación al ligar los nombres de algunos asentamientos judíos en España con nombres bíblicos.

Por ejemplo:

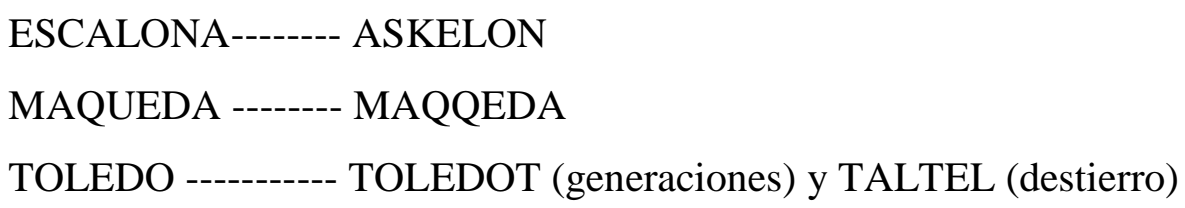

Sin embargo estos datos no son suficiente prueba para confirmar la hipótesis.

A partir del siglo III de la e.c. encontramos pruebas fehacientes de asentamientos judíos.

${ }^{1}$ Publicado en Cuaderno Judaico n ${ }^{\circ}$ 23, páginas 67 - 89 
- Se sabe que Tito y Vespasíano deportaron un gran número de prisioneros de Judea, además,

- la arqueología permitió exhumar hallazgos importantes, como son monedas judías, procedentes de Tarragona y el epitafio judío más antiguo encontrado en Armeria, que data justamente del siglo III.

Después de la caída del Imperio Romano, (ocurrida en el siglo V) hasta el año 710, los visigodos, pueblo germánico, gobernaron España. Los visigodos profesaban por fe el arrianismo, (secta cristiana), que en términos de convivencia social significó para los judíos una cierta tolerancia religiosa.

En el año 587 el rey Recaredo abjuró del arrianismo en favor del catolicismo durante el tercer concilio de Toledo.

En el año 612, el rey Sisebuto ordena el bautismo forzado a los judíos so pena de expulsión. Este hecho marca el inicio de los actos concretos de intolerancia religiosa.

Desde el 710 hasta 1492, España estuvo bajo el dominio musulmán, los reinos cristianos se repliegan al norte de la Península y durante ese período vamos a encontrar un resurgimiento de la civilización en todas las áreas del saber.

Los judíos como protagonistas importantes de este renacimiento, van a vivir la llamada «Edad de oro del judaismo español» durante los siglos XI y XII, 1492 marca el fin de un proceso que se inicia en España en 1391 con una serie de matanzas y persecuciones dirigidas contra la comunidad judía.

Finalmente, el edicto de expulsión firmado por los reyes católicos el 31 de marzo de 1492 en la ciudad de Granada, pone fin a la dominación musulmana y con ello se apaga un momento brillante de la cultura judeo-arábiga en la Península. 
Luego de la expulsión, la mitad de los judíos de España huyeron a Portugal, el gobierno portugués los recibió por un período limitado de ocho meses mediante el pago de un tributo de protección.

En Portugal se vivió un proceso de conversiones forzadas desde 1496 y en 1497 se produce la expulsión definitiva.

La diáspora judía se dirigió principalmente al norte de Africa, Norteamérica y América.

\section{ESPAÑA: VIDA Y CULTURA}

Para comenzar este tema, debemos pensar que los judíos vivieron alternadamente bajo el dominio cristiano o musulmán.

Respecto del carácter del cristianismo durante su proceso de consolidación, como del islamismo, las palabras del profesor Salo W. Barón, lo ilustran con gran claridad:

«El cristianismo que empezó como una religión pacífica, más bien ultraterrenal habíase transformado entonces en un credo de jóvenes pueblos celosos y combativos que consideraban la guerra como un deber tanto religioso como civil. En cambio los musulmanes, cuyo credo comenzó como una religión de la espada y cuyo fundador fue más un constructor de imperios que un profeta, habíanse apaciguado a la sazón, para gozar los frutos de una civilización avanzada».

España durante ocho siglos de dominación musulmana se constituyó como el punto de encuentro entre Oriente y Occidente.

El maridaje cultural producido entre judíos, musulmanes y cristianos, dio como resultado hombres grandes y sabios y éstos a su vez, crearon un tipo de cultura excepcional por sus obras. Aquellos personajes pertenecientes a la comunidad judía de la época, especialmente 
tres figuras de la literatura judeo-española, serán motivo de nuestro interés en esta ocasión.

Podríamos afirmar con propiedad que el florecimiento cultural que tuvo lugar durante la conducción del Califa Abderraman II (812-961) la civilización musulmana llegó a su apogeo y los judíos vivieron la llamada «Edad de oro del judaísmo español».

El sistema de gobierno que los musulmanes impusieron se caracterizó por la tolerancia religiosa para con los grupos dominados. Judíos y cristianos vivían bajo la calidad de DHIMI (protegidos) y para ello debían pagar un tributo, la GIZIA.

Esta sociedad dio como resultado un cipo de hombre judío, que para poder caracterizarlo es necesario contextualizar su forma de vida durante este período:

Como ya vimos la comunidad judía en España data desde el siglo III. Durante ciertos períodos de la dominación cristianas los judíos se vieron forzados a usar distintivos, a sufrir matanzas y ver diezmada su población y sus bienes, todo ello debido al resurgimiento periódico del «anti-judaísmo» por parte de la población y autoridades cristianas.

Desde un punto de vista económico, la población judía tuvo una importante participación en el desarrollo comercial de España. Prácticamente no hubo actividad económica en la que los judíos no estuvieran presentes y alcanzaran éxito. Hubo financieros, abogados, prestamistas, poetas, ministros de estado, marinos, etc.

Si bien es cierto que existían en la época razones religiosas para estimular el sentimiento anti-judío, como el deicidio, la profanación de la hostia, el crimen ritual etc., hay un motivo de orden económico que está en la base de este mecanismo mediante el cual las prédicas de ios monjes y religiosos exaltaban los odios del pueblo.

El cobro de impuestos es uno de los motivos más concretos que explican la odiosidad y las revueltas dirigidas hacia la comunidad judía. El que un personaje judío o en algunos casos toda una comunidad judía, fuera la que recaudara los impuestos al pueblo, llegó a ser una actividad muy recurrente y los cristianos llegaron a ver en los judíos la causa de todos sus 
males, pobrezas y miserias, si agregamos a ello las acusaciones religiosas como el crimen ritual, la profanación de la hostia y el deicidío que algunos predicadores se encargaban de recordar en sus sermones, el panorama no podía ser peor para los judíos.

El mecanismo usado para la recaudación de impuestos, era el que un judío adinerado, o en algunos casos una comunidad entera, pagara por adelantado al rey la totalidad de los impuestos del año, dinero que la corona necesitaba para financiar sus empresas bélicas, principalmente las cruzadas.

Lo que los judíos recibían a cambio de esta actividad, no eran beneficios económicos, sino la posibilidad de obtener libertades personales de tipo social.

Judá Haleví fue médico de profesión, al igual que Maimónides, pero su fama se debe a su creación poética, tanto en hebreo como en árabe y también en la lengua vulgar de los cristianos, todo esto hace que Menéndez y Pelayo diga que «quizá muy probablemente el primer poeta conocido en lengua castellana sea Judá Haleví», no sin razón era conocido con el apodo de «el castellano».

Las inquietudes y preocupaciones, ausentes en su vida por su condición de hombre rico, comenzaron a aparecer al hacerse presente en su conciencia el estado de degradación en que vivía su pueblo. Este sentimiento cada vez más profundo en Judá es la veta que da origen a sus Siónidas, composiciones poéticas en las que se canta el amor a Sión (Israel). Iser Guinzburg al respecto nos dice:

«Las crueles persecuciones que padecían los judíos en los países vecinos, la opresión de los israelitas por los nuevos gobernantes mahometanos, los almorávides, junto con el desprecio que unos y otros demostraban por el pueblo hebreo por el hecho de carecer de un territorio y de un gobierno propios, lo cual era tenido entonces como la mejor prueba de que Dios había quitado su amparo a los judíos, todo esto amargó la vida de Judá Haleví. Abandonó Toledo y se radicó en la Córdoba morisca, pero 
también allí encontró el mismo odio y desprecio».

El mismo Judá se lamenta en sus poemas de esta manera:

« ¿Tenemos acaso en el oriente $\mathrm{o}$ en el occidente algún lugar en que podamos estar seguros?.

Es mi deseo ser amparado por las alas de Dios y estar allí donde estuvieron mis antepasados».

Por lo que se puede deducir de sus poemas, se supone que Judá pese a los ruegos de única hija y de sus amigos abandonó España y se dirigió a Tierra Santa, pero en aquella época Jerusalém estaba ocupada por los cristianos, quienes al parecer no dieron una bienvenida amable a Judá, quien se queja diciendo:

«Ver tu gloria anhelaba mi corazón y cuando finalmente llegué a tu lugar sagrado, me ahuyentaron de allí como a un impuro. Debo so portar el destino de mi pueblo, inclinarme paciente bajo la vara del opresor, porque no quiero servir a ningún Dios y sólo a ti he de implorar».

Rabí Judá Haleví vivió en la época comprendida entre Salomón ibn Gabirol y Maimónides. Gabirol, Haleví y Maimónides representan el momento más brillante del judaísmo español.

Natan Gesang nos dice que Judá llegó a convertirse en el poeta nacional de su pueblo y lo caracteriza de la siguiente manera:

«El poeta nacional es el emisario del pueblo, se levanta con humildad delante del todopoderoso y reza en su lenguaje, poéticamente, por su nación e implora por su liberación. El poeta sabe que está habilitado para esta misión y derrama en palabras de oro las esperanzas de su pueblo. Canta lo que el pueblo siente en las profundidades de su corazón y no es capaz de expresarlo. Por lo general el 
pueblo suele ser tartamudo, siente algo, desea algo, aspira a algo, su corazón rebosa de dolor y de amor, pero le falta el lenguaje. El poeta nacional da expresión a los sentimientos del pueblo. Encuentra la forma para sus anhelos, fija una modalidad determinada para su voluntad. Recoge las partículas de ideas que se esconden en el alma del pueblo, las esperanzas y aspiraciones que se remontan en el aire, las ideas en su estado desnudo, las reviste de ropajes espléndidos y entona el cántico grandioso de la redención».

Tanto es así, que este sentimiento hacía Rabí Judá es expresado de esta manera por el poeta Enrique Heine:

«Fue pura, veraz, sin macula

su canción, como su alma.

Tan hermosa que el Creador

cuando la hubo creado,

satisfecho la besó;

y guarda el eco del beso,

consagrada por tal gracia

cada canción del poeta».

En cuanto a su producción poética, tenemos que establecer dos épocas de producción, que los autores suelen llamar «edad juvenil»y «edad madura» respectivamente.

El primer período de creación de Judá está fuertemente marcado por una estética del goce y la belleza, incluso por la sensualidad y el erotismo.

Los motivos lírico predominantes son el vino, la amistad, el amor, la belleza femenina y el paisaje natural. Estas poesías tienen el valor y la maestría de mostrarnos imágenes, casi relucientes, de cada uno de los sentimientos que las inspira.

Como ya está dicho, corresponden a los primeros años del poeta, y desde un análisis que relacione la biografía del autor con su producción literaria, estos temas son el resultado de la vida de un hombre hijo de una familia rica, educado con esmero y sin 
ninguna preocupación o posibles sufrimientos. La historia nos cuenta además que Judá fue afortunado en el amor y que pudo casarse con la mujer que amaba.

Para ilustrarlo antes dicho, leamos algunos versos:

«Salud oh, gentil gacela.

Fuego es tu amor, que mi corazón abraza.

Dulce el jugo de tu boca, como de fuente divina.

Negras como la noche son tus guedejas.

Cual el sol en el cénit tu rostro brilla...»

Otro:

«Mi corazón amoroso

por tu corazón palpita

cual de una fuente eternal

de tu alma brota mi vida,

y en tus manos nacaradas

está entera el alma mía».

Otro:

«Al borde de un arroyuelo

está una linda paloma

con encantos que hechizan los ojos, cualquiera posee oro y plata, pero nunca tesoro como mi paloma.

¿A dónde querrá volarse?

pregunto confuso y admirado, muchos nidos podrán hallarse pero nunca como el corazón mío».

Otro:

«Jugando con ella en mis rodillas 


$$
\begin{aligned}
& \text { vio su imagen en mis pupilas, } \\
& \text { sonriendo maliciosa } \\
& \text { meciéndose en mis brazos, } \\
& \text { coh manos cristalinas } \\
& \text { acariciando mis mejillas } \\
& \text { y besándome en los ojos, } \\
& \text { me decía sorprendida: } \\
& \text { ícuán bella es la imagen } \\
& \text { que veo en tus pupilas! } \\
& \text { sin pensar por un momento } \\
& \text { que no besaba mis ojos, } \\
& \text { sino su propia imagen». }
\end{aligned}
$$

Sobre este punto Iser Guinzburg nos dice:

$$
\begin{aligned}
& \text { «El vino, el amor y la poesía le ocupaban constantemente, cantando jubiloso iba } \\
& \text { de orgía en orgía, abriendo su corazón a las alegres toledanas y andaluzas que } \\
& \text { embriagaban sus sentidos. La exuberante naturaleza de las orillas del Tajo, del } \\
& \text { Guadalquivir y del Darro, avivaban su fresco ingenio, su alma vehemente } \\
& \text { fundíase en canciones de alegría y de amor». }
\end{aligned}
$$

Sin embargo esta veta va a dejar paso a otra, tanto o más genial, pero sin duda llena de sufrimiento y dolor.

Judá Haleví vivió las matanzas de 1109, esto junto a la progresiva conciencia del estado de degradación en que vivía el resto de su pueblo, que no tenían la dicha de ser ricos como él, fueron cambiando los temas de sus composiciones.

El canto por una patria perdida y añorada es el motivo central de sus siónidas, magníficas composiciones poéticas, que hicieron merecedor a Judá del título de poeta nacional. Este es el llamado período de «edad madura» de Judá, Iser Guinzburg lo describe así:

«Sólo en la edad madura acentuóse en él más y más el sentimiento religioso, los grandes disturbios y guerras, en los cuales los judíos eran los primeros en sufrir, 
quebrantaron su corazón, entonces se sumerge en un mundo religioso, y sus arpegios vibrantes se convierten en acentos suplicantes y quejumbrosos».

El Cuzarí es después de las siónidas, su obra más conocida. El libro es una instancia en la que podemos apreciar, además de lo estrictamente literario, su pensamiento filosófico.

El Cuzarí o «Libro de argumentación y demostración en ayuda de la fe desfalleciente» es una narración en forma de diálogo en la que un rabino a través de la argumentación convence al rey de los cuzares a convertirse al judaísmo. El, al meditar sobre las razones del rabino, se convence de que el judaísmo es la verdadera religión y desde entonces él y su pueblo aceptan las leyes de Moisés.

Lo que Judá hace a través del Cuzarí, es abordar la empresa de explicar el judaísmo, tanto al mundo exterior como a sus propios adherentes. Es una obra dirigida tanto a judíos como a gentiles que se enmarca dentro de la lógica imperante en la época de las famosas disputas religiosas.

El judaismo es según la obra, la única religión verdadera, el simple hecho de ser el pueblo judío el que recibió la Torá en el monte Sinaí, lo hace acreedor de tal honra.

Por otra parte, nuestro autor era versado en filosofía, como muchos de sus compatriotas de las clases cultas, fue un estudioso de la filosofía heleno-arábiga y de la ética de las mismas fuentes, pero pronto comprendió la futilidad de algunas respuestas frente a las realidades duras y evidentes de su época, y el Cuzarí es la respuesta que Judá propone.

La imposibilidad de que el conocimiento humano ofrezca repuestas, radica en el hecho de que por su naturaleza imperfecta es completamente inadecuado para penetrar en los hondos misterios de la existencia, en esa medida sólo la lorá, puede dar respuestas

Para concluir, quisiera recordar la leyenda de su muerte; se cuenta que Rabi Judá, llegando a los pies del muro de los lamentos, en su peregrinación a Jerusalém, ocupada entonces por los cruzados, fue aplastado por el caballo de un sarraceno, y en ese mismo lugar murió 
cantando su gran siónida.

\section{MOISES BEN MAIMON: MAIMONIDES}

Maimónides nació en Córdoba en el año 1135 y murió en Fostat, Egipto en el año 1204. Su padre era Dayán (juez), de la comunidad de Córdoba y de él aprendió Maimónides sus primeros conocimientos judaicos. Maimónides estudió Talmud, medicina, astronomía y filosofía.

Apenas había cumplido trece años, cuando los almohades conquistaron su ciudad natal y la familia se vio obligada a huir, para evitar tener que aceptar el islamismo a la fuerza.

Radicada en Fez la familia de Maimónides, a pesar de tener que ocultar su fe, Maimónides escribe a sus hermanos perseguidos del Yemen la siguiente carta:

«Porque Dios en su misericordia, nos ha distinguido, escogiendo a los hijos de Israel como representantes de la verdadera religión, por eso nos odian los pueblos de la tierra...Desde la revelación en el monte Sinaí, no ha pasado ni una sola generación sin que el judaísmo y sus adeptos dejasen de ser perseguidos. Las naciones cegadas por su odio, nos combatieron de tres diferentes formas, primero por medio de las armas como Nabucodonosor, Tito y Adriano, con el fin de exterminarnos, después por medio de la mentira y del intento de persuadirnos sofísticamente, como los persas, los griegos y romanos, con el propósito de desprestigiar nuestra religión por medio de argumentos y finalmente, recurriendo a la astucia, como el cristianismo y el islamismo, que merodean disfrazados de judaísmo, para hacer así desaparecer nuestra fe...Las revelaciones de Nazareth y la Meca (cristianismo e islamismo respectivamente) son respecto del judaísmo, lo mismo que una imagen artísticamente pintada en relación con un ser vivo y vigoroso. Sólo los niños o los locos pueden tomar un retrato por un ser vivo...Y ahora hermanos míos, meditad acerca de esas verdades y no os dejéis desanimar por las dificultades que os ha tocado en suerte vencer. Esos sufrimientos os han sido deparados para poner a prueba y para comprobar que los descendientes de Jacob, los hijos de quienes recibieron la Torá junto al monte Sinaí, poseen la verdadera religión».

Esta carta nos permite destacar algunos aspectos importantes del pensamiento de 
Maimónídes y del momento histórico que le toca vivir.

Maimónides es conocido como teólogo y filósofo. Como teólogo su obra más importante es su comentario a la Mishná, en donde demuestra su completo dominio de las fuentes judías y la lucidez para poder discernir el fallo más simple y preciso ante un problema en el que las fuentes judías presentan más de una solución.

Su «comentario» se convirtió en manual obligado para quienes debían resolver sobre alguna cuestión de LEY El lenguaje claro y preciso y la adecuada selección de los temas hacen de esta obra un ejemplo en materia religiosa.

Sin embargo es su obra filosófica la que ha tenido un impacto universal mayor. El «Guía de los perplejos» es una obra que comprende tres volúmenes en los cuales Maimónides desarrolla el tema de la oposición entre la verdad filosófica y la verdad religiosa, es decir el gran tema de la relación entre ciencia y religión.

Sin duda aquí, por la complejidad de estos asuntos, sólo podremos mostrar de manera gruesa las principales ideas que aparecen en el «Guía de los perplejos» y de las principales ideas filosóficas de Maimónides.

En primer término debemos decir que la obra está dirigida a la comunidad de intelectuales judíos que en aquella época se encontraban perplejos ante las verdades que desde la filosofía griega, especialmente Platón y Aristóteles, empezaron a conocerse en Europa y que se mostraban en grandes contradicciones frente a lo que las escrituras afirmaban.

Las escuelas de traductores árabes fueron el puentes entre la antigüedad greco-latina y la Europa Medieval, España fue en este sentido un punto de encuentro entre el pensamiento oriental representado por el judaismo y el islamismo, y el pensamiento europeo que se desarrolló en las universidades cristianas y que se benefició de la cultura clásica gracias a la mediación de árabes y judíos. 
Los puntos en cuestión que debatián los filósofos de la época, eran afirmaciones de las fuentes bíblicas frente a la de los filósofos griegos, en relación a temas como; la relación entre fe y razón, la eternidad el mundo, las pruebas de la existencia de Dios y los atributos divinos, principalmente.

El «Guía» es un brillante esfuerzo por conciliar la fe y la razón sirviéndose del aparato conceptual aristotélico.

En primer lugar trata sobre la interpretación de la Ley (Torá), luego las pruebas de ta existencia de Dios, la incorporeidad y unidad de la causa primera, las leyes de la naturaleza, la creación y la conservación del mundo y finalmente se ocupa de los ritos y la conducta.

El problema de la relación fe-razón, Maimónides lo resuelve postulando que la ciencia de la Ley, y la filosofía son conocimientos de naturaleza distinta, pero no inconciliables, pues ambas proceden de la misma fuente, es decir Dios, y por esto no puede haber contradicción. Con esto Maimónides deja obsoleto el planteamiento de la «doble verdad», y su tesis pasa a ocupar el centro de las discusiones tanto con Tomás de Aquino en París, Roberto Grosseteste y John Pacham en Oxford, y Alberto el grande en Colonia etc.

La cuestión sobre la eternidad del mundo, fue un tema de gran polémica durante la época que nos ocupa, pues las fuentes bíblicas afirman que el mundo fue creado, es decir finito en el tiempo, y la cosmología aristotélica afirmaba por su parte que el cosmos está en un eterno movimiento, de esta manera la filosofía aristotélica concebía a Dios como un «Noésis-Noeseos», es decir, pensamiento que se piensa a sí mismo.

La solución a la controversia nuevamente surge de las tesis de Maimónides quien sostuvo en este punto, que si bien la razón puede dar pruebas lógicas que afirman la eternidad del mundo, estas pruebas no son concluyentes, y por otra parte, la creación del mundo, es decir su temporalidad, no puede ser refutada con argumentos lógicos.

Finalmente, Maimónides afirma que no puede decidirse racionalmente este asunto, es decir 
con argumentos lógicos, filosóficos o científicos, y que por lo tanto el creyente será quien opte por lo que su fe enseña.

En relación al tema de la existencia de Dios debemos señalar que Maimónides es receptor de toda la elaboración que los árabes habían hecho durante el siglo XII, como Alfarabí y Avicena, quienes se fundan a su vez en las ideas de Aristóteles.

El problema de aceptar directamente el argumento aristotélico sobre este punto, es que él parte de la premisa de que el cosmos es eterno, premisa que está en contradicción con las escrituras, y que éste necesita un motor que lo mueva, este motor también sería eterno, pues el cosmos lo es.

Maimónides resuelve la contradicción separando la tesis aristotélica y aceptando sólo una parte de ella. El problema de la existencia de Dios debe pensarse separadamente del problema de si el mundo es eterno o no.

En esa medida la cuestión de la existencia de Dios se centra en la necesidad de admitir un primer motor para explicar la existencia del actual movimiento. Así la explicación es que toda causa tiene una causa anterior, pero la creación no admite una serie infinita de causas anteriores, por lo tanto debemos suponer un primer motor inmóvil que sea la causa de todo lo demás.

Finalmente, en lo que respecta a los atributos divinos Maimónides se postula por la predicación negativa de Dios, es decir, que de Dios sólo podemos afirmar lo que no es, pero no lo que es, puesto que nuestro intelecto es incapaz de tal conocimiento.

\section{BAJYA BEN JOSEF IBN PAKUDA}

\section{EL AUTOR Y SU OBRA:}


Bajya ben Yosef ibn Pakuda fue un poeta y un filósofo que nació en España en el año 1040 y murió aproximadamente en el 1110 e.c.

Su obra más conocida es «Doctrina de los deberes de los corazones», conocida en árabe como «Jovot Halvavot».

Esta es una obra de carácter filosófico y moral, destinada a un receptor judío. Esta característica tiene relevancia puesto que para comprenderla cabalmente es necesario conocer todos los elementos que son atraídos constantemente por la escritura.

Es una obra que se inserta dentro de la tradición bíblica y talmúdica en tanto asume los mismos mecanismos de interpretación y de escritura.

Desde otro punto de vista, Jovot Halvavot puede ser estudiada a través de las categorías de la tradición «gentil», es decir, analizando el contexto cultural en que surge, en este caso la España Medieval y los constructos teóricos que operan en la época.

De su vida han llegado hasta nuestros días muy pocos antecedentes que permitan establecer una biografía más documentada que la que aquí detallamos:

Se le conoció con el apodo de dayán (juez), apodo que hace referencia a su actuación como magistrado de un tribunal rabínico en Zaragoza.

Podemos decir con certeza, que se benefició del ambiente cultural que a la fecha existía en la corte de Zaragoza. Ibn Pakuda vivió en la generación siguiente a la de ibn Gabirol y, como en éste yen la mayor parte de los autores hispano-hebreos del período, predominaba en ibn Pakuda una marcada tendencia moral-religiosa que se traduce en la creación de una teología moral que provocó gran aceptación en las masas, prueba de ello es que su obra más importante, Doctrina de los deberes de los corazones fue muy leída entre la gente de su época, pese que a nivel de autoridades judaicas o de la doctrina oficial no ejerció notable influencia. 
Doctrina de los deberes de los corazones (Jovot halvavot) es una obra de carácter filosóficareligiosa de la que no puede obviarse su concepción como obra estética y su valor poético. El principio fundamental de su doctrina es la superioridad de la comunión con Dios respecto de la observancia de las leyes y de la conducta moral, concepto que revela el fondo místico de la filosofía de ibn Pakuda, filosofía que está fuertemente influida por el kalam árabe, por el neoplatonismo y por la literatura ascética y sufi. El tema central de Jovot halvavot es que lo principal en la vida debe ser el sentimiento religioso y que las ciencias, incluso la ciencia de la Torá y la misma Ley, al menos en lo que tiene de prescripciones rituales, está muy por debajo de los deberes de la conciencia, traducidos en una vida santa, llena de temor de Dios.

Bajya ibn Pakuda produjo también poesía, toda ella de índole religiosa, pero los textos de su obra poética no se encuentran a nuestra disposición.

Sin duda Jovot halvavot (Doctrina de los deberes de los corazones) es su obra más importante tanto en su época como para quienes vinieron después. La importancia de ella se puede mostrar a través de lo que David Gonzalo Maeso nos dice: »Es muy posible que esta obra influyera en los escolásticos, y algunas palmarias coincidencias dan pie para afirmar que Santo Tomás pudo tener en cuenta las pruebas de la existencia de Dios expuestas por Bajya ibn Pakuda en su Jovot Halvavot».

El propósito que guía la actividad de este autor es perfeccionar la vida religiosa y moral de su pueblo a través del estudio de su asunto que se encontraba olvidado por los tratados. La mayor preocupación de ibn Pakuda es que las formas religiosas amenazan vaciarse de contenidos. Los motivos que lo guían en su tarea son, principalmente dos:

a) La ausencia de una obra que tratara explícitamente sobre los deberes de los corazones, $\mathrm{y}$,

b) La necesidad de ella: ibn Pakuda siente temor al igual que sus antepasados de la variedad de las prácticas religiosas. 
Al respecto señala:

«Quien quiera que se consagre solamente al estudio de la Torá, es semejante al ateo, como está dicho: 'Durante largo tiempo Israel no tuvo ya Dios verdadero, sacerdotes que fuesen maestros y ni aún la Tora'. Es necesario consagrarse a la Tora y a la caridad». (Crónicas 15:3)

El primer paso estructurante de Jovot halvavot es la certeza del autor de que está cumpliendo con la palabra sagrada y con la tradición al ocuparse de una obra como ésta:

«Dios da la sabiduría: el conocimiento y la inteligencia salen de su boca». (Proverbios 51:6)

Los vértices sobre los que se apoya corresponden sin duda a la Torá y la tradición. La importancia de este hecho es que ibn Pakuda se plantea como un continuador, un perfeccionador de la vida moral y religiosa de su pueblo. Debemos notar esto y destacarlo en toda su importancia, pues reviste un carácter definitorio y estructurante de una particular forma y visión de mundo y de ella podemos inferir los supuestos que guían el quehacer de nuestro autor. A nosotros nos corresponde actualizar y poner en circuito comunicativo su obra.

Dentro de este marco podemos entender el procedimiento de Pakuda cuando dice que el conocimiento se divide en tres partes o en tres ciencias: la ciencia superior es la Teología ella permite el acercamiento de Dios y la comprensión de la Torá. Asimismo, otorga su justo lugar a cada una de las otras dos, a la ciencia de las cosa creadas, llamada en árabe Al ilm al tibi, y las matemáticas, llamada en árabe AI Üm al-ilahi y que comprende la aritmética, la geometría, la astronomía y la música.

La ciencia de la Torá a su vez, se divide en dos partes, en deberes interiores y exteriores. Los deberes interiores son los del corazón. Esta es la razón por la cual ibn Pakuda dice que se debe estudiar por amor: 
«Estudiad por amor, toda gloria vendrá por añadidura».

(Deuteronomio 30:22)

Al estudiar la tradición, ibn Pakuda comprobó que los deberes interiores estaban abandonados en los escritos y concluye que los tratados se limitaban a tres propósitos:

La exégesis y la aclaración del lenguaje y la gramática; presentar en forma sumaria los preceptos, e implantar la Torá por medio de demostraciones y de refutaciones a los incrédulos.

La conclusión a la que llega es la siguiente:

«He investigado estos escritos, pero no encontré entre ellos ningún libro consagrado especialmente a los deberes interiores. He comprobado que la ciencia de los deberes del corazón estaba completamente abandonada: Nadie se ha ocupado de manera sistemática de sus principios y sus distintos aspectos».

El resultado de este proceso introspectivo que las verifica en la conciencia del autor, y su puesta en práctica da como resultado la obra que a continuación presentamos.

a) La obra como Midrash:

La obra que nos ocupa debe ser entendida, en primer término, como un producto literario que se inserta dentro de una tradición, la tradición bíblica del pueblo hebreo, que abarca ya, más de cinco mil años.

Esta tradición milenaria ha permanecido hasta nuestros días, pero no ha sido invulnerable al paso del tiempo ni a los cambios suscitados en la historia del pueblo judío.

Se puede notar una evolución constante a través de la historia, evolución que ha ido al ritmo de los cambios culturales e intelectuales de las diferentes comunidades, en los 
diferentes países en los que se han asentado.

Los productos culturales y en particular los productos literarios del pueblo judío, han ido adoptando formas y contenidos diferentes, manifiestos expresamente por los requerimientos de la comunidad. Es así, entonces, que a partir de la entrega de la Revelación en el monte Sinaí, la literatura judía ha adaptado sus estructuras respondiendo, principalmente, a requerimientos religiosos, por un lado, y a requerimientos legales, por el otro.

Podemos decir que hasta el siglo V a.e.c. el carácter de la literatura judía fue la oralidad. Y delimitamos ese siglo porque fue en él cuando se sintió la necesidad de instaurar el cánon definitivo de los primeros textos. Ello porque ya se conocían desde el siglo X, los primeros escritos (conocidos por la crítica bíblica como Documento J), ello, sumado a la tradición oral que se transmitía generacionalmente, aumentó en gran medida el caudal tradicional.

Si quisiéramos graficar, escuetamente, el panorama general de la literatura hebrea tradicional, obtendríamos el esquema que presentamos en la página 81 y que representa toda la Revelación que Moisés recibió en el Sinaí.

En el contexto anterior, la Doctrinas de los deberes de los corazones se inscribe dentro de la literatura midráshica, es decir, aquella literatura que tiende a la edificación moral a través de la interpretación de las escrituras

\section{ESQUEMA SIMPLIFICADO DE LA EVOLUCIÓN DE LAS FUENTES JUDAICAS}

(Según la profesora Ana María Tapia Adler, 1990)

Una palabra sobre Midrash

La Enciclopedia Judaica Castellana define el término de la siguiente forma:

«MIDRASH (de la raíz hebrea Darosh, investigar» buscar). Método de interpretación de la Biblia, que pasa del sentido literal del texto (Peshat) 
al estudio del significado más profundo. Se comentaba un versículo de las Escrituras y ese comentario se analizaba, hasta obtener una interpretación nueva» o la aplicación a un caso práctico. En esa forma se desarrollaron dos tipos de Midrash, según el texto legalista (midrash halajá) o filosófico, ético y teológico (midrash hagadá) de la Biblia (...).

El midrash halajá se distingue del midrash hagadá no sólo por el contenido, sino también por el carácter más circunspecto del primero, ya que la halajá era base de legislación y sus interpretaciones tenían fuerza legal».

El origen del midrash debe buscarse en la insuficiencia de los códigos bíblicos para abarcar todos los aspectos de la vida diaria y para corresponder a los cambios constantes en la vida nacional. 


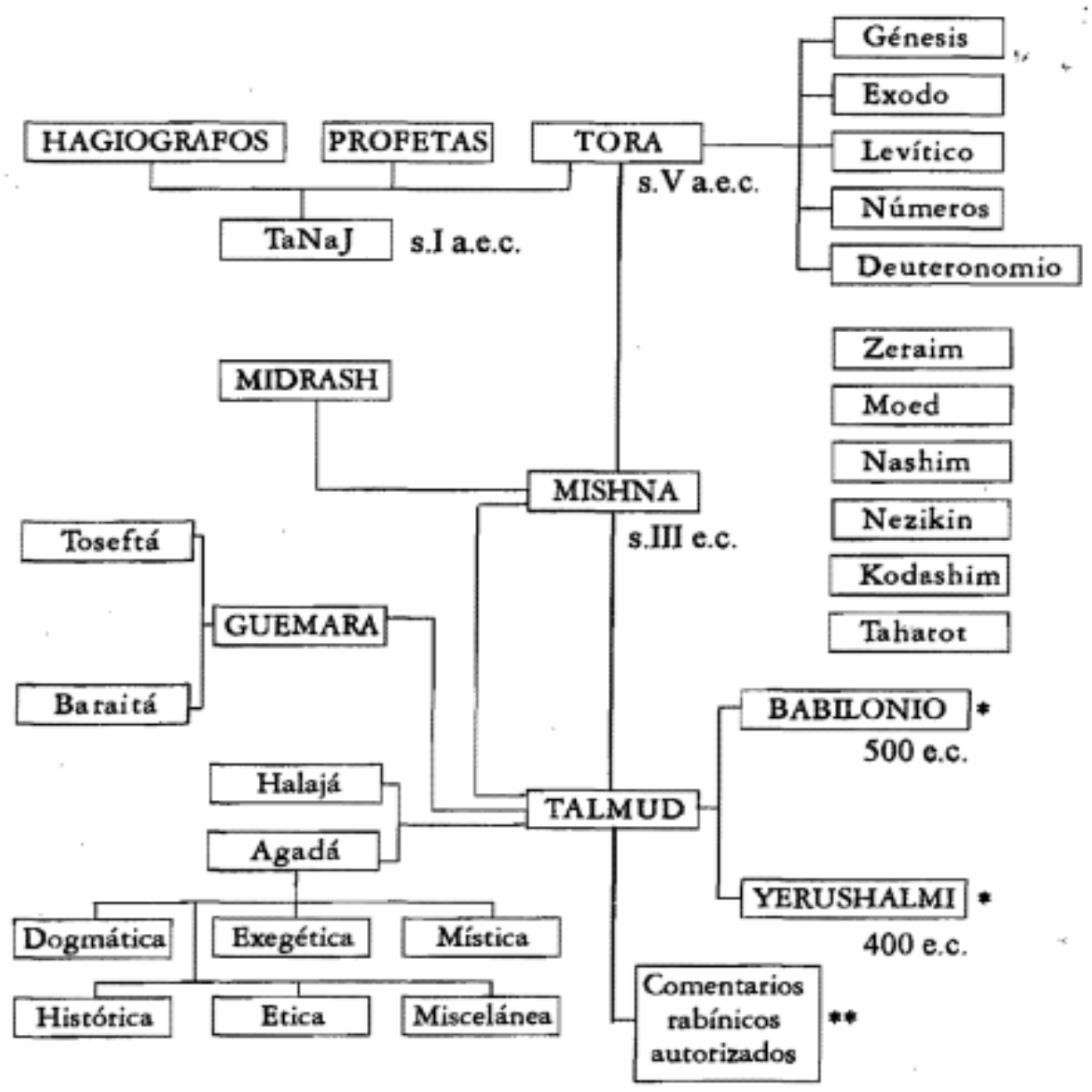

* Se dividen en seis ordenes, al igual que la Mishná.

** Su fuerza legal deriva del Talmud, dada su interpretación en el sentido halájico.

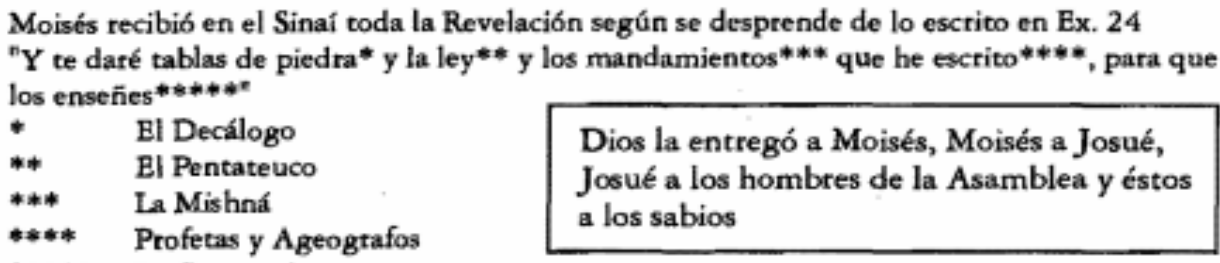

*:*** Profetas y Ageografos Josué a los hombres de la Asamblea y éstos a los sabios

La obra Doctrina de los deberes de los corazones puede calificarse como literatura midráshica, en tanto es un intento por desentrañar un sentido no suficientemente explícito en la Escrituras, que se traduzca en una nueva interpretación, y en última instancia, en una conducta mejor. Considerando que tanto el modelo como el método principal de este tipo de literatura es el de la Biblia. 
La vinculación estrecha del pueblo judío con la palabra ha llevado a esta proliferación de literatura a partir de un modelo incuestionable: La Biblia. En ella se encuentran los métodos y los tópicos útiles y verdaderos para el hombre. Este modelo se traduce en normas de conducta, en principios axiológicos que rigen todos los aspectos de la vida de un judío.

Para nuestro enfoque interesa destacar dos premisas básicas del mandato divino al pueblo, cuales son: estudiar y enseñar.

La enseñanza es la que ha dado como resultado el caudal de literatura exegética que constituye la base de la tradición judaica y que se muestra con claridad en el esquema anterior.

El Midrash se articula dentro de esta corriente de la enseñanza. La Doctrina de los deberes de los corazones se inscribe también en esta línea, en tanto es una intento por dar una nueva interpretación a las Escrituras.

La obra, entonces, se plantea en una línea de sucesión ininterrumpida, adhiriendo a una forma establecida por la tradición y a un método asumido como correcto y verdadero.

Podemos decir que la interpretación judía, en sus variadas formas, puede reducirse a un esquema básico invariable:

\section{TEXTO + COMENTARIO}

Aún cuando su estructura es mucho más rica y compleja, también la Doctrina de los deberes de los corazones puede reducirse a este simple esquema. Su estructura última es el texto bíblico más un extenso comentario que se traduce en la enunciación y estudio de los diez principios (pórticos) que constituyen la obra y que buscan una aplicación real en la vida del hombre.

La presencia de la Escritura, tanto como de la tradición sinagogal, se da como una 
estructura, más que como fuente de motivos o temas. La presencia abrumadora de citas bíblicas y talmúdicas y de los tratados de los doctores y maestros del judaísmo, especialmente de AVOT, están dando cuenta de un fenómeno mayor.

Podemos decir que la estructura del discurso de la obra, se entreteje en forma y contenido con estas citas, como se aprecia en el siguiente pasaje:

«Y si el hombre se apoya sobre la inmensidad de su riqueza ella la huye, y queda solo. Se acuesta rico, muere despojado; abre los ojos y todo ha desaparecido (Job 27:19). Que no se atormente, entonces para enriquecerse, y no aplique en esto su inteligencia. ¿Proseguirá contemplando lo que va a desaparecer?. Pues la fortuna está hecha con alas y como el águila, levanta su vuelo hacia los cielos (Proverbios 23:4,5). En medio de sus días el hombre debe abandonar todo, o bien, él no goza más de nada, pues Dios se lo impide (Jeremías 17:11).

Su riqueza es para él un depósito que cuida hasta el día en que debe ser entregado a su verdadero destinatario (Eclesiastés 6:2). Dios confía al pecador el cuidado de reuniría y aumentarla, pero para darla a quien es por El amado. El perverso acumula, pero el justo se viste (Job 27: 17)».

Es un discurso que se plantea en continuación tan estrecha y natural con el discurso de la tradición que no tiene conflictos en aparecer lleno de citas. Por el contrario, este hecho se constituye como requisito y una prueba de autoridad de lo que se dice. El fenómeno que se produce, más que de intertextualidad, puede denominarse de cotextualidad, es decir, un texto al lado del otro; el texto modelo otorgando estatus y autoridad al texto continuador.

El método utilizado por el Midrash, en este caso, Midrash hagadá (filosófico-religioso), privilegia el uso del ejemplo y la comparación, métodos privilegiados también en la tradición.

La construcción de parábolas constituye un nivel de mayor elaboración. Este método responde a la necesidad de enseñar de manera simple y directa, con un lenguaje claro, el sentido que se intenta mostrar al hombre común. Este objetivo está señalado por el autor: 
«Mi único deseo es que se me comprenda. Con el vocabulario de que dispongo, diré lo que estará presente en mi espíritu en lo que concierne a los deberes del corazón» .

Dentro de lo que son las citas bíblicas y atracción hacia el texto de otros tratados, podemos establecer niveles que dan cuenta de un uso progresivo de la creación personal y un desapego a lo textual.

El sentido general de la obra emana de la necesidad que existiese un tratado sobre los deberes del corazón, debido a la ausencia expresa en la tradición, aún cuando a la vez, sí se percibe su presencia -en forma más o menos velada-, en las Escrituras. La explicitación de los mismos da como resultado una obra nueva en cuanto ai tema, pero necesariamente tradicional en cuanto a la forma, como ya hemos dicho: Texto más comentario.

Sin embargo, dentro de lo que es asumir la tradición y hacerla propia, lo mismo que el discurso ajeno, se puede notar claramente una fuerza centrífuga que opera en sentido contrario, y que da como resultado la puesta en escena de la belleza de la obra. Esta fuerza centrífuga que opera en el texto se da en forma diferenciada, por cuanto se pueden distinguir grados o niveles.

Un primer nivel es aquel en que el discurso ajeno aparece claramente señalado como tal, este caso es el de mayor frecuencia:

«Los justos y los que se abandonan a El se confían en el Señor y lo exaltan los corazones rectos (Salmos 64: 11).'Luz y felicidad irradian de ellos' canta David (Salmos 97:11)».

Un segundo nivel es aquél en que lo dicho, y que pertenece en rigor a un discurso ajeno, aparece sólo marcado por una alusión:

«Un sabio ha dicho: Me sorprendo que aquel que pasa dos veces por el canal de la orina y de la sangre, pueda enorgullecerse e hinchar su corazón». 
Un tercer nivel consiste en la ausencia total de texto, es decir, aparece el rótulo de un ejemplo, una historia o una fábula conocida, y con esto se apela a la competencia respecto del conocimiento de la tradición del lector:

«... Pero quien espera que Dios se lo ofrezca sin el conducto de los actos es un simple o un tonto, es Zimri, exigiendo el salario de Pinjas».

Estos tres niveles que hemos señalado están en conjunto, apuntando a la concepción de lector que se maneja en el texto y a su grado de participación en la construcción del sentido de la obra. Es importante tener en cuenta que siendo una obra de un autor judío y con un contenido judío, el lector supuesto será, necesariamente también, un lector judío, quien tendrá la competencia necesaria para actualizar los textos atraídos por la escritura y llenar los vacíos de los rótulos que hemos señalado.

Este es un texto que se completa en su realización, en la capacidad del lector para actualizar los elementos que aparecen aludidos, tanto como para llenar lo que el autor está tratando de decir:

«Hemos establecido suficientemente el deber de contemplar las criaturas y de sacar de ello las pruebas de la divina sabiduría.

Y tú, por ti mismo, has de comprenderlo».

Por último, dentro del despliegue de estos niveles, la construcción de parábolas para entregar el mensaje, se establece a nuestro juicio, llamado centrífuga, (sólo en el sentido de que se presenta en apariencia como creación personal), es decir son ellas lo que podríamos llamar el verdadero discurso (poético) de nuestro autor.

Por otro lado, son también el método por excelencia de la literatura midráshica, y sin duda una de las más bellas formas de enseñar.

\section{PALABRAS FINALES}


A modo de conclusión y sabiendo de antemano que la presentación de los autores sólo pretende ser un panorama, la intención es que haya sido lo suficientemente motivador como para acercarnos a conocer un poco más de la obra de estos personajes, que vivieron en la España de los siglos XI y XII y que contribuyeron notablemente al desarrollo del conocimiento en cada una de las áreas en las que trabajaron; filosofía, medicina, poesía, religión, comercio, astronomía, matemáticas, etc.

Quisiera destacar como inspiración central de este trabajo, lo que estas figuras representan a través de su forma de concebir al mundo, al hombre y su sentido, es decir, como un todo orientado hacia su creador, a la búsqueda de respuestas trascendentes, de una manera equilibrada, integradora y llena de fe.

Estos elementos, que a la luz de nuestra forma de vida aparecen tan lejanos, eran para los hombres de entonces de vital importancia.

Para nosotros hoy la forma más común de expresarnos es a través de lo particular, de las especializaciones cada vez más profundas que nos dejan en una situación de cada vez mayor incomunicación entre los que tienen acceso al conocimiento y la mayoría sumida en la ignorancia. 